\title{
Identifying gender differences in the independent effects of personality and psychological well-being on two broad affect components of subjective well-being
}

\author{
R.A. Burns ${ }^{\mathrm{a}, \mathrm{b}, *}$, M.A. Machin ${ }^{\mathrm{a}}$ \\ ${ }^{a}$ Department of Psychology, University of Southern Queensland, Toowoomba, Queensland 4350, Australia \\ ${ }^{\mathrm{b}}$ Ageing Research Unit, Centre for Mental Health Research, Australian National University, Canberra, ACT 0200, Australia
}

\section{A R T I C L E I N F O}

\section{Article history:}

Received 8 April 2009

Received in revised form 5 August 2009

Accepted 11 August 2009

Available online 8 September 2009

\section{Keywords:}

Subjective well-being

Psychological well-being

Personality

\begin{abstract}
A B S T R A C T
Subjective well-being (SWB) is defined in terms of positive and negative affect whilst psychological wellbeing (PWB) reflects self-referent attitudes of mastery and self-acceptance. Whilst both SWB and PWB are associated with personality, concurrent analysis is limited. This study $(n=679)$ reports on a teacher sample in which personality, SWB and PWB were measured. Results indicated moderate correlations between variables. Hierarchical regression controlled for personality and identified PWB as a significant predictor of SWB. Separate predictors of negative and positive affect support the need to assess both SWB affective components. As the most significant predictor of positive affect the inclusion of PWB is needed in future well-being research.
\end{abstract}

(c) 2009 Elsevier Ltd. All rights reserved.

\section{Introduction}

Considerable effort has sought to extend notions of well-being and wellness as the absence of ill-being states, with psychological constructs such as self-concept, mastery, and resilience that have been demonstrated as important components of positive wellbeing (e.g. Burns, 1979). Increasingly, findings that identify the impact of such positive psychology constructs are informing government policy on health and well-being (e.g. Huppert, 2008).

Two main approaches to the study of well-being have been described (Ryan \& Deci, 2001). The subjective well-being (SWB) approach focuses on those experiences that make life either enjoyable or unpleasant. The identification of two broad affect states, positive and negative affect, has been well supported (e.g. Watson, Clark, \& Tellegen, 1988) and increased pleasant and decreased negative valence states typically defines optimal SWB (Vittersø, 2001). The need to discern between these affect states is important. For example, the negative affect and anxiety/depression link is well established (e.g. Watson et al., 1988), and the importance of positive emotions in broadening and expanding individuals' cognitive and behavioural tendencies, has been reported (Fredrickson, 2003).

Other important facets of SWB are related to its degree of temporal stability. Dynamic Equilibrium Theory (DET) proposes that SWB states are malleable to life events and experiences (Headey

\footnotetext{
* Corresponding author. Address: Department of Psychology, University of Southern Queensland, Toowoomba, Queensland 4350, Australia. Tel.: +61 026125 3132.

E-mail address: richard.burns@anu.edu.au (R.A. Burns).
}

\& Wearing, 1989), but that changes in affect generally return to their set-point level (Kahneman, 1999), a significant proportion of which appears genetically pre-determined (Lykken \& Tellegen, 1996). However, much DET research has used life satisfaction measures which fail to describe different affective components, and much cross-sectional and longitudinal data fails to capture the extent and duration of changes from set-point levels. Consequently, the extent genetics determine SWB is likely over-estimated (Huppert, 2005). Headey (2008) has recently argued that DET describes SWB for most, although for a significant minority high in extraversion and/or neuroticism, long-term changes in life satisfaction can be substantial.

In contrast to SWB, the psychological well-being (PWB) approach emphasises characteristics which are related to optimal SWB. Due to the reactive nature of SWB components, where variability would make them poor indicators of long-term wellness, PWB proponents (e.g. Ryff \& Singer, 1998) have challenged SWB as limited in describing long-term positive functioning, and a fallible indicator of healthy living. PWB may function as a predictor of extent and duration of SWB reactivity. Ryff (1989) operationalised a multi-dimensional model of PWB that tapped six related concepts of well-being, including autonomy, personal growth, selfacceptance, purpose in life, environmental mastery, and positive relations with others, which are seemingly more temporally stable (Ryff \& Singer, 1998). This clash of well-being paradigms has led to differing definitions of wellness and different issues concerning the causes, consequences, and dynamics of well-being, yet terms like affect, well-being and personality are frequently cited topics (e.g. Schmutte \& Ryff, 1997). However, the extension of the wellbeing-personality literature with PWB models is less detailed. 


\subsection{Well-being and personality}

Generally using SWB models, associations between well-being and personality are frequently reported. Extraversion is typically related to positive affect and neuroticism to negative affect (e.g. Costa \& McCrae, 1980; Diener \& Lucas, 1999). DeNeve and Cooper's (1998) meta-analysis identified extraversion and agreeableness as consistently positively correlated with global SWB, whilst neuroticism was consistently negatively correlated.

Personality also appears related to SWB reactivity. Individuals with higher SWB possess attribution styles which are self-promoting and subsequently contribute to higher levels of satisfaction and happiness and report stressful life events in a less negative way than those with lower SWB (Lyubomirsky \& Ross, 1999). Similarly, Kling, Ryff, Love, and Essex (2003) demonstrated how neuroticism and openness to experience predicted increases in negative affect after a stressful life event, whilst extraversion and openness to experience predicted increases in positive affect. That openness is positively related to both positive and negative affect has also been reported in large longitudinal panel data (Headey \& Wearing, 1989). These findings suggest that the impact of stressful experiences on well-being may be influenced by personality. Also, the effect of different personality traits on different SWB components supports the need to discriminate between SWB components (Ryan \& Deci, 2001).

There are clearly well-established relationships between SWB and personality. However, the role of PWB in the personalitySWB link is limited. One example includes Schmutte and Ryff's (1997) analysis of a five-factor personality inventory and Ryff's model of PWB which controlled for affect. Since only small to moderate correlations between the dimensions of PWB and personality remained after controlling for affect, there are significant nonoverlapping effects between personality and PWB.

There has been little attempt to replicate Schmutte and Ryff's (1997) findings. Moreover, the factorial validity of Ryff's (1989) 6-PWB scales, has been questioned (e.g. Springer \& Hauser, 2006). Whilst support for the 'a priori' six-factor model has been received (e.g. Clarke, Marshall, Ryff, \& Wheaton, 2001) strong correlations between four PWB variables: environmental mastery $(E)$, personal growth $(G)$, purpose in life (P), self-acceptance (S) (EGPS), suggests that these variables reflect one super-ordinate $P W B$ factor (Abbott et al., 2006). A recent analysis (Burns \& Machin, 2009) supported this amended PWB structure and importantly also differentiated items between this modified three-factor PWB structure and two SWB affect components, positive and negative affect.

\subsection{Aim}

The current study will identify the unique effects of PWB on two broad SWB affect states, positive and negative affect, after controlling for personality and demographics effects. Analyses will test for gender differences on all of the variables. A multi-groups analysis will test whether a personality and PWB predictor model of SWB is invariant across the genders.

\section{Method}

\subsection{Participants and design}

Data was drawn from an organisational climate study $(N=679)$ comprising three samples of high-school teachers, from privatelyfunded schools in the Australian Capital Territory, Australia $(n=253)$, school-teacher members of the Norwegian teacher union ( $n=250)$, and from International Schools $(n=176)$ worldwide. Predominantly female (63\%), almost half of the sample (46.2\%) was aged between 30 and 55 years of age, although $63.2 \%$ of the Norwegian sample was aged 45 years and older. Many participants did not live in the immediate vicinity of the university and so accessed the survey through a secure web facility, run and monitored by the technical services staff within the University of Southern Queensland's Department of Psychology. The University's Human Research Ethics Committee provided approval for the study.

\section{Measures}

\subsection{Psychological well-being (PWB)}

A 54-item version of Ryff's (1989) PWB scales assessed six dimensions of PWB: environmental mastery $(E)$, personal growth $(G)$, purpose in life (P), self-acceptance (S), (EGPS; $\alpha=.785$ ); autonomy (A; $\alpha=.613$ ); and positive relations (PR; $\alpha=.777$ ), with participants indicating their response on a 6-point Likert-type scale, with higher scores on each scale indicating greater well-being on each dimension. Factor analysis of the PWB variables (not reported here) supported previous analyses (Burns \& Machin, 2009), which combine 4 of the PWB variables E, G, P, S to create a super-ordinate first-order PWB factor, EGPS.

\subsection{Subjective well-being (SWB)}

The Positive And Negative Affect Schedule (PANAS; Watson et al., 1988) assessed SWB with 20-items relating to positive affect $(\alpha=.877)$ and negative affect $(\alpha=.885)$. Individuals indicated their response on a 5 -point Likert-type scale, with higher scores on each scale indicating greater well-being on that dimension.

\subsection{Five-factor personality structure}

A 50 item personality measure from the International Personality Item Pool (IPIP; Grucza \& Goldberg, 2007) assessed five domains: neuroticism $(\alpha=.871)$, extraversion $(\alpha=.789)$, agreeableness ( $\alpha=.771$ ), openness to experience ( $\alpha=.737)$, and conscientiousness $(\alpha=.839)$. Comparative analysis of 11 personality inventories suggests that the IPIP scales are well-validated measures of the five-factor personality structure (Grucza \& Goldberg, 2007). All internal reliabilities for all the sub-scales of these measures were within acceptable levels.

\subsection{Statistical procedure}

Analyses were computed using SPSS and AMOS v17. Bi-variate correlations tested the associations between all PWB, personality and SWB variables, and $t$-tests identified gender differences on these variables. Hierarchical regression analysis controlled for demographics and personality variables to test the PWB effect on positive and negative affect. A multi-group Structural Equation Model (SEM) tested whether the PWB and personality regression model identified in the hierarchical regression analyses was invariant between gender.

\section{Results}

Moderate to strong bi-variate correlations between SWB, PWB and personality were highly significant $(p<.001)$, except for the non-significant coefficients reported between openness to experience with neuroticism, positive relations, and conscientiousness (Table 1). Except for two negative coefficients with negative affect and neuroticism, positive affect reported positive associations with all other variables, whilst only neuroticism and openness to experience reported positive associations with negative affect. The 
Table 1

Descriptives and correlations on the personality, SWB and PWB measures.

\begin{tabular}{|c|c|c|c|c|c|c|c|c|c|c|c|c|c|}
\hline \multirow[t]{2}{*}{ Variables } & \multicolumn{2}{|l|}{ Male } & \multicolumn{2}{|l|}{ Female } & \multirow[t]{2}{*}{1} & \multirow[t]{2}{*}{2} & \multirow[t]{2}{*}{3} & \multirow[t]{2}{*}{4} & \multirow[t]{2}{*}{5} & \multirow[t]{2}{*}{6} & \multirow[t]{2}{*}{7} & \multirow[t]{2}{*}{8} & \multirow[t]{2}{*}{9} \\
\hline & M & SD & M & SD & & & & & & & & & \\
\hline [1] Positive Affect ${ }^{\mathrm{a}}$ & -.07 & 6.89 & .04 & 6.71 & 1 & & & & & & & & \\
\hline [2] Negative Affect ${ }^{a}$ & -.20 & 6.83 & $.12^{* * * *}$ & 7.49 & $-.224^{* * *}$ & 1 & & & & & & & \\
\hline [3] EGPS ${ }^{\mathrm{a}, \mathrm{b}}$ & -.18 & 1.04 & $.11^{* * * *}$ & .88 & $.589^{* * *}$ & $-.237^{* * *}$ & 1 & & & & & & \\
\hline [4] Positive Relations ${ }^{\mathrm{a}}$ & -.08 & .84 & .05 & .95 & $.182^{* * * *}$ & $-.386^{* * *}$ & $.314^{* * *}$ & 1 & & & & & \\
\hline [5] Autonomy & .11 & .79 & $-.06^{* *}$ & .90 & $.250^{* * *}$ & $-.293^{* * *}$ & $.305^{* * *}$ & $.247^{* * *}$ & 1 & & & & \\
\hline [6] Extraversion & 35.97 & 5.49 & 35.29 & 5.87 & $.373^{* * *}$ & $-.207^{* * *}$ & $.456^{* * *}$ & $.382^{* * *}$ & $.342^{* * *}$ & 1 & & & \\
\hline [7] Neuroticism & 23.59 & 6.54 & 23.35 & 7.05 & $-.442^{* * *}$ & $.633^{* * *}$ & $-.553^{* * *}$ & $-.481^{* * *}$ & $-.499^{* * * *}$ & $-.422^{* * *}$ & 1 & & \\
\hline [8] Openness & 38.26 & 5.85 & 38.53 & 5.29 & $.148^{* * *}$ & $.137^{* * *}$ & $.200^{* * *}$ & -.031 & $.165^{* * *}$ & $.234^{* * *}$ & -.049 & 1 & \\
\hline [9] Agreeableness & 37.23 & 5.28 & $38.48^{* *}$ & 4.98 & $.408^{* * *}$ & $-.368^{* * *}$ & $.462^{* * *}$ & $.270^{* * *}$ & $.276^{* * *}$ & $.213^{* * *}$ & $-.535^{* * *}$ & $.182^{* * *}$ & 1 \\
\hline [10] Conscientiousness & 38.11 & 6.00 & $39.07^{*}$ & 5.74 & $.463^{* * *}$ & $-.340^{* * *}$ & $.537^{* * *}$ & $.241^{* * * *}$ & $.406^{* * *}$ & $.305^{* * *}$ & $-.546^{* * *}$ & .043 & $.408^{* * *}$ \\
\hline
\end{tabular}

${ }^{*} p<.05$.

*** $p<.01$.

**** $p<.001$

a Variables were saved in SPSS using the regression method following factor analysis.

b EGPS - super-ordinate PWB factor computed following Burns and Machin (2009).

super-ordinate factor, EGPS, reported the strongest association with positive affect, whilst neuroticism reported the strongest association with negative affect. With only $40 \%$ shared variance, the association between neuroticism and negative affect does not indicate serious collinearity. Positive associations between openness to experience with both positive and negative affect suggest that this personality trait is related to increases in both SWB domains. A $t$-test between genders indicated females reporting statistically higher on negative affect, EGPS, agreeableness and conscientiousness, whilst males scored higher on autonomy.

To test the first hypothesis, hierarchical regression analyses (Table 2) tested the effects of PWB on positive and negative affect (Model 3), controlling first for demographics (Model 1) and then personality variables (Model 2). PWB contributed considerably more explained variance in positive affect, and also a small additional amount of variance in negative affect. EGPS was the strongest predictor of positive affect, with moderate coefficients for extraversion, agreeableness and conscientiousness. Unlike the bivariate associations reported earlier (Table 1), neuroticism, openness to experience and autonomy no longer reported significant associations with positive affect. Despite a positive bi-variate correlation, positive relations now reported a small significant negative coefficient with positive affect. Gender reported a statistically significant effect on positive affect in the final model indicating a suppression effect with the inclusion of the PWB variables. These suppression effects are small in effect size and possibly a consequence of sample size. Apart from a negative effect for positive relations, PWB variables contributed little to explained variance in negative affect. Instead, the strongest predictor of negative affect was neuroticism. Openness to experience reported a moderate positive coefficient, whilst increasing age, agreeableness and conscientiousness were negative predictors of negative affect. Despite a significant negative bi-variate correlation, EGPS was now a significant positive predictor of negative affect. A reported Variance Inflation Factor (VIF) high of 2.147 and a Condition Index (CI) high of 3.297, suggest that issues of collinearity were not identified.

The three suppression effects identified in the regression analyses were investigated further. Partial correlations between EGPS and negative affect partialed out each personality variable in turn to test which variable interacted with EGPS to change its bi-variate negative relationship with negative affect (Table 3 ). Two smaller effects were reported for conscientiousness and agreeableness. A strong effect was identified with neuroticism and reveals that for those high in neuroticism, increased EGPS is associated with higher levels of negative affect (Fig. 1). This is an important finding that suggests that high levels of PWB are not protective of negative SWB states for all individuals.

Partial correlations revealed that extraversion, neuroticism and EGPS all influenced the positive bi-variate correlation between positive relations and positive affect. Individual suppression effects were not significant. Instead, the relationship between positive relations and positive affect was influenced by a two-way interaction between neuroticism and extraversion $(r=-.095 ; p=.013)$ and a three-way interaction between neuroticism, extraversion and EGPS $(r=-.104 ; p=.007)$. The small size of the suppression

Table 2

Hierarchical regression of SWB on demographics, PWB and personality.

\begin{tabular}{|c|c|c|c|c|c|c|c|c|c|c|c|c|}
\hline & \multicolumn{6}{|c|}{ Positive affect } & \multicolumn{6}{|c|}{ Negative affect } \\
\hline & \multicolumn{2}{|c|}{$\begin{array}{l}\text { Model } 1 \\
\left(\text { adj. } R^{2}=.000\right)\end{array}$} & \multicolumn{2}{|c|}{$\begin{array}{l}\text { Model } 2 \\
\left.\text { (adj. } R^{2}=.326\right)\end{array}$} & \multicolumn{2}{|c|}{$\begin{array}{l}\text { Model } 3 \\
\left.\text { (adj. } R^{2}=.405\right)\end{array}$} & \multicolumn{2}{|c|}{$\begin{array}{l}\text { Model } 1 \\
\left(\text { adj. } R^{2}=.063\right)\end{array}$} & \multicolumn{2}{|c|}{$\begin{array}{l}\text { Model } 2 \\
\left(\text { adj. } R^{2}=.455\right)\end{array}$} & \multicolumn{2}{|c|}{$\begin{array}{l}\text { Model } 3 \\
\left.\text { (adj. } R^{2}=.469\right)\end{array}$} \\
\hline & Beta & Sig. & Beta & Sig. & Beta & Sig. & Beta & Sig. & Beta & Sig. & Beta & Sig. \\
\hline Gender & .000 & .992 & -.038 & .242 & -.073 & .019 & -.025 & .509 & .008 & .777 & .004 & .886 \\
\hline Age & -.045 & .248 & -.059 & .079 & -.015 & .642 & -.260 & .000 & -.168 & .000 & -.148 & .000 \\
\hline Extraversion & & & .179 & .000 & .123 & .001 & & & -.006 & .850 & -.008 & .817 \\
\hline Neuroticism & & & -.129 & .004 & -.078 & .100 & & & .562 & .000 & .560 & .000 \\
\hline Openness To Experience & & & .053 & .113 & .012 & .715 & & & .177 & .000 & .152 & .000 \\
\hline Agreeableness & & & .184 & .000 & .134 & .000 & & & -.116 & .001 & -.129 & .000 \\
\hline Conscientiousness & & & .267 & .000 & .163 & .000 & & & .017 & .616 & -.028 & .438 \\
\hline EGPS $^{a}$ & & & & & .384 & .000 & & & & & .136 & .001 \\
\hline Positive Relations & & & & & -.083 & .019 & & & & & -.101 & .002 \\
\hline Autonomy & & & & & -.038 & .285 & & & & & .006 & .863 \\
\hline
\end{tabular}

a EGPS - super-ordinate PWB factor computed following Burns \& Machin (2009). 
Table 3

Correlations between EGPS and negative affect controlling for personality.

\begin{tabular}{lll}
\hline & \multicolumn{2}{l}{ Negative affect } \\
\cline { 2 - 3 } & $r$ & $p$ \\
\hline EGPS $^{\text {a }}$ & -.237 & .000 \\
Controlling for & & \\
Extraversion & -.164 & .000 \\
Neuroticism & $\mathbf{. 1 7 6}$ & $\mathbf{. 0 0 0}$ \\
Openness to experience & -.273 & .000 \\
Conscientiousness & -.081 & .035 \\
Agreeableness & -.068 & $\mathbf{. 0 7 5}$ \\
\hline
\end{tabular}

a EGPS - super-ordinate PWB factor computed following Burns \& Machin (2009).

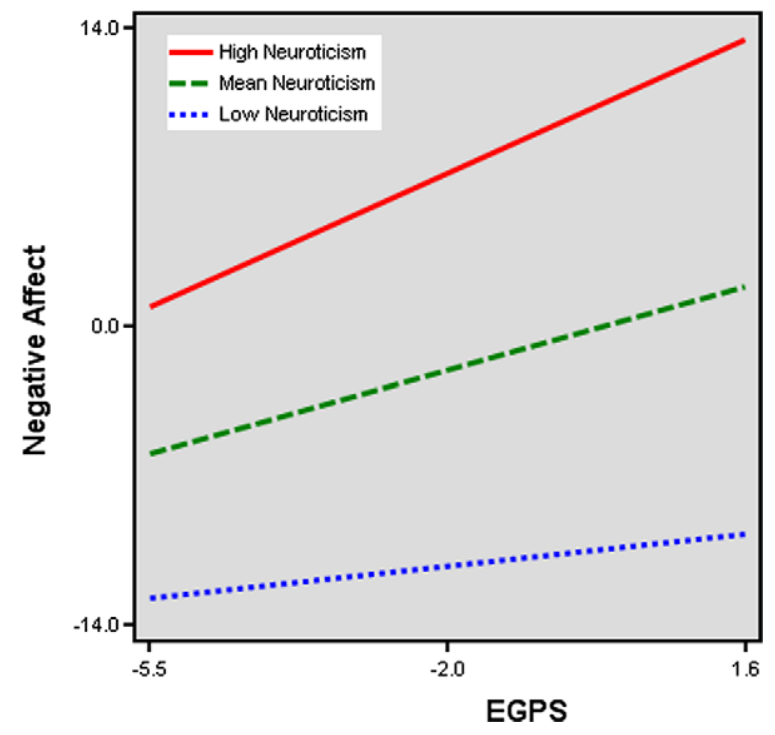

Fig. 1. Interaction between EGPS and Neuroticism on negative affect.

effect reported in the hierarchical analysis suggests this effect is only statistically significant. Similarly, the suppression effect with gender on positive affect is likely due to the significant differences between gender on the PWB variable EGPS reported earlier (Table 1).

\subsection{Multiple-group analysis of SWB regressed on $P W B$ and personality}

We evaluated whether the significant effects reported in the regression models (Table 2 ) were consistent between gender. A Structural Equation Model (SEM; Fig. 2) supported the earlier hierarchical analyses in identifying the key predictors of positive affect and negative affect. Autonomy was not related to either affect and was omitted from the SEM. Model fit revealed very good Goodness of Fit indices (GFI; $\chi^{2}=8.294, \quad \mathrm{df}=8, \quad p=.405 ; \quad \mathrm{AGFI}=.985$; $\mathrm{CFI}=1.00$; RMSEA $=.007(.000-.046))$, whilst results from the single group analyses reported GFI within acceptable bounds for both males $\left(\chi^{2}=18.460, \quad \mathrm{df}=8, \quad p=.017 ; \quad\right.$ AGFI $=.914 ; \quad$ CFI $=.988$; RMSEA $=.073(.029-.116))$ and females $\left(\chi^{2}=18.999, \mathrm{df}=8\right.$, $p=.015 ;$ AGFI $=.945 ;$ CFI $=.992 ;$ RMSEA $=.057(.024-.090))$. Next, a simultaneous multi-group analysis was conducted in which all parameters were free to vary across gender.

The Critical Ratio of Differences test (CR) of an unconstrained model of the combined sample indicated several regression and covariance paths, and error and variance terms, to vary between genders where a CR score of $>1.96$ is significant $(p=.05)$. Most of these gender differences still reported significant $(p<.05)$ coefficients in the same direction, but two regression paths demonstrated a strong effect of gender variance. The coefficient for

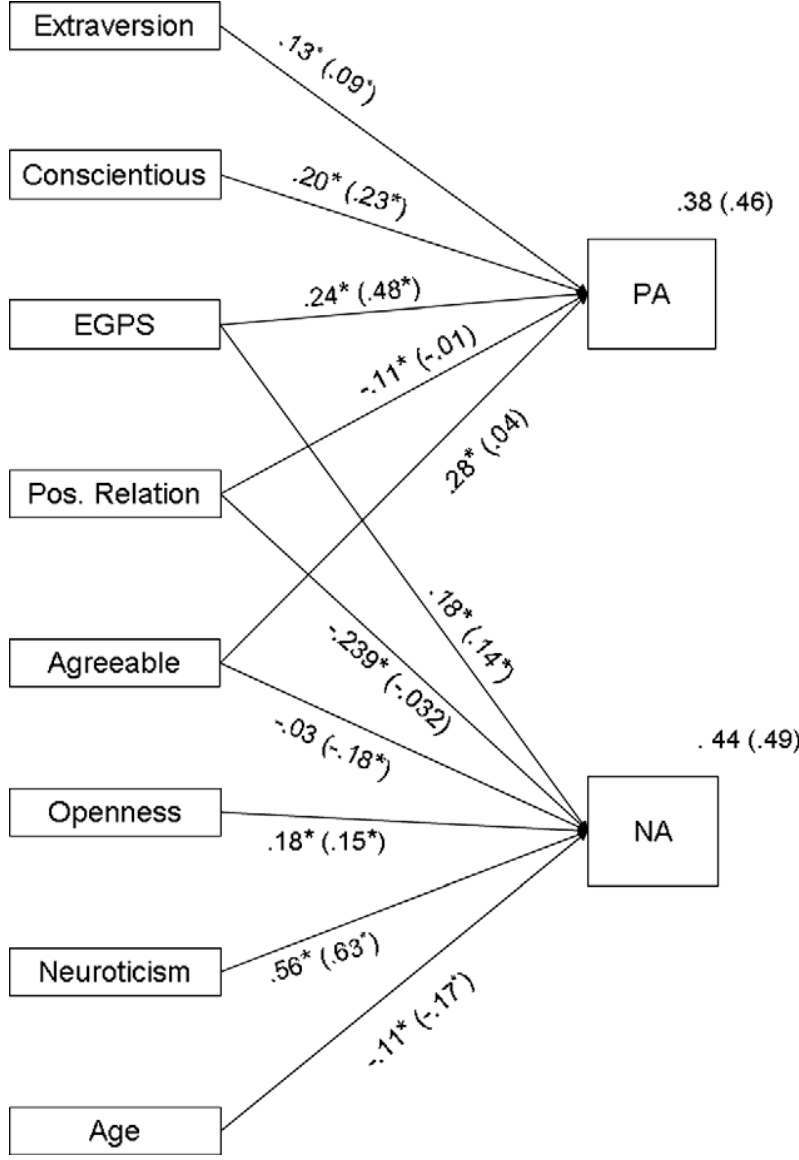

Fig. 2. A path model of the demographic, PWB and personality predictor model of SWB. Note: Coefficients are reported for males and with females in parentheses. Significant paths $(p<.05)$ are indicated by *.

agreeableness predicting negative affect was not significant for males, whilst the coefficient for positive relations on negative affect was not significant for females. Constraining these two nonsignificant regression paths to zero, resulted in two more paths reflecting structural variance between genders; females reported non-significant coefficients for positive relations predicting positive affect, and agreeableness predicting positive affect.

Analysis of Chi-Square indicated that this constrained model performed significantly worse (Table 4). However, inspection of the modification index values suggested including a covariance path between positive and negative affect error terms would significantly improve fit and it was acceptable to assume that this covariance path reflected correlation between the dependent variables (Byrne, 2001). Chi-Square revealed no significant difference between this partially constrained model (with four constrained paths and a covariance path between the error terms for positive and negative affect) and the unconstrained model although inspection of the other GFI revealed this partially constrained model to report better fit to the data. This constrained model did not explain comparable amounts of variance in SWB affect states for both genders. For females, this final model explained greater amounts of variance in positive (46\%) and negative affect (49\%), than for males for both positive (38\%) and negative affect (44\%).

\section{Discussion}

This study identified strong independent effects of personality and PWB on two SWB components, positive and negative affect. Whilst associations between all variables were reported, VIF and 
Table 4

Comparisons of GFI for unconstrained and constrained demographic, PWB, and Personality predictor models of SWB.

\begin{tabular}{|c|c|c|c|c|c|c|c|}
\hline & $\chi^{2}$ & DF & $p$ & AGFI & $\mathrm{CFI}$ & $\begin{array}{l}\text { RMSEA } \\
(95 \% \mathrm{CI})\end{array}$ & $\begin{array}{l}\text { Sig of } \chi^{2} \text { of } \\
\text { difference }\end{array}$ \\
\hline Unconstrained & 22.497 & 14 & .069 & .953 & .996 & $.030(.000-.052)$ & - \\
\hline $\begin{array}{l}\text { Partially constrained model } \\
\text { Constraining the following parameters to } 0 \text { : } \\
\text { Males agreeableness on NA }\end{array}$ & & & & & & & \\
\hline $\begin{array}{l}\text { Females positive relations on NA } \\
\text { Females positive relations on PA } \\
\text { Females on agreeableness on PA }\end{array}$ & 39.652 & 20 & .006 & .944 & .991 & $.038(.020-.055)$ & 0.009 \\
\hline $\begin{array}{l}\text { Partially constrained model } \\
\text { Constraining the following parameters to } 0 \text { : } \\
\text { Males agreeableness on NA }\end{array}$ & & & & & & & \\
\hline $\begin{array}{l}\text { Females positive relations on NA } \\
\text { Females positive relations on PA } \\
\text { Females on agreeableness on PA } \\
\text { Including covariance path between PA and NA }\end{array}$ & 24.547 & 18 & .138 & .960 & .997 & $.023(.000-.044)$ & 0.727 \\
\hline
\end{tabular}

$\chi^{2}$ difference test computed with the unconstrained model as the baseline model.

CI scores were well below levels at which collinearity would be an issue. By incorporating a modified structure (Burns \& Machin, 2009) of Ryff's (1989) PWB scales, this study identified EGPS, a super-ordinate factor of four PWB variables, as the strongest predictor of positive affect, over and above the influence of personality. Prior research into the personality-SWB link (e.g. Costa \& McCrae, 1980; Diener \& Lucas, 1999) was supported with extraversion, agreeableness and conscientiousness reporting moderate positive coefficients with positive affect. However, the strength of this association is weakened by the inclusion of the PWB variables. Neuroticism reported the strongest effect on negative affect whilst openness to experience and agreeableness respectively reported moderate positive and negative coefficients. That openness to experience was a positive predictor of both positive and negative affect supports previous findings (Headey \& Wearing, 1989). Of the PWB variables, only positive relations was related to lower levels of negative affect which suggests that increased social support is related to better SWB outcomes. This appears related to the function of social support to buffer the effects of negative experiences on SWB, since a converse positive effect for positive relations on PA was not reported. Multi-groups analysis revealed gender differences in regression paths predicting SWB, but key predictors of SWB, such as neuroticism with negative affect, and EGPS with positive affect, were invariant across gender. Importantly, by controlling for the effects of personality, including its shared variance with SWB, these results demonstrate that PWB greatly increases the prediction of SWB, particularly positive affect, and is not just capturing the same variance that personality measures typically predict.

The relationship with personality and PWB on SWB is not a straightforward one. A strong and significant interaction effect was reported for EGPS with neuroticism on negative affect. Although increased EGPS may typically be a benefit, our analyses revealed that for those high in neuroticism, higher EGPS is related to higher levels of negative affect. This is an important finding since the well-being literature typically assumes 'a more is better' approach.

EGPS can not be reduced to a method artefact since it has been reported in two separate analyses (Abbott et al., 2006; Burns \& Machin, 2009). Whilst items between the four variables that comprise EGPS appear to reflect different content, they nevertheless fail to differentiate between the four PWB variables that comprise EGPS. The EGPS items appear to reflect cognitive components of self-concept at a general level (Burns, 1979), and may also reflect notions of self-determinism (Ryan \& Deci, 2001), personal resourcefulness, positivity and mindfulness (Seligman, 2003). Fur- ther investigations into the construct validity of Ryff's PWB scales are warranted, to determine whether the scales reflect other validated measures of self-referent attitudes. Still, a strong independent association revealed that EGPS was a significant predictor of SWB and the implications of this result should not be minimised. It is important to investigate the nature of this relationship further, but clearly the PWB variables are significant predictors of SWB.

Several limitations need to be highlighted. Firstly, the data is cross-sectional. Whilst prior theory and research may posit temporal relationships, these findings will need to be extended to longitudinal designs to assess these established cross-sectional relationships across time, particularly to demonstrate the influence of PWB as a predictor of SWB outcomes. It cannot be ignored that SWB states may be quite strong predictors of PWB, or that a reciprocal relationship may exist.

A further issue is the extent to which PWB is an outcome of personality traits. A longitudinal study has recently identified personality, measured at age 16 and 26, as a strong predictor of PWB at age 52 (Abbott et al., 2008). However, Abbott et al. (2008) were unable to test the reverse causation of the PWB, personality and SWB link since the PWB scales were not available for the earlier waves. The current authors propose a model in which personality and PWB are distinct cognitive constructs that relate to different aspects of an array of self-referent attitudes. Support for such a model has previously been identified, though comprising slightly different psychological constructs. Judge, Erez, Bono, and Thoresen (2003) identified a correlated four-factor structure comprising independent cognitive components of generalised self-efficacy, self-esteem, neuroticism, and locus of control which reflect a broad latent trait of 'core self-evaluations'.

A further weakness relates to the conceptual overlap of PWB, SWB and personality variables. The distinct but related nature of the PWB and SWB variables has previously been identified (Burns \& Machin, 2009) and has been supported here. Also, previously identified associations between personality and well-being were also supported (e.g. Costa \& McCrae, 1980; DeNeve \& Cooper, 1998; Diener \& Lucas, 1999). Issues relating to the degree to which these constructs overlap are frequently raised, yet the bi-variate correlations from this study suggest only $40 \%$ and $35 \%$ shared variance between neuroticism and negative affect, and extraversion and positive affect, respectively. A similar conclusion could be drawn about the overlap between PWB and personality since the highest amount of shared variance between these constructs was $31 \%$. Clearly, whilst there are strong associations between the well-being and personality variables, the findings from this study 
indicate greater independence of the PWB, SWB and personality constructs.

Usual methodological concerns relating to response bias and social-response desirability may have influenced participant response to well-being and personality. In particular, the data was drawn from three teacher cohorts and cohort effects were not partialed out. Whilst unpublished work by the authors has indicated that cohort effects are not a significant issue for the pattern of relationships reported here, it should be considered that the cultural diversity was relatively homogenous and that these results are drawn from primarily wealthy and western industrialised countries. Two of the samples were drawn from Australian and Norwegian schoolteacher populations. Even the International school-teacher sample mostly comprised UK, Australian/NZ and US/Canadian schoolteachers. Therefore we urge caution over the generalisation of these findings to non-western or collectivist societies.

\section{Conclusion}

This study has demonstrated that after controlling for personality and demographic effects, PWB appears to be a significant factor in determining SWB. PWB's importance lies in providing a direction for interventions that by focusing on developing facets of individuals' PWB, may instil longer-lasting attitudinal changes that engender feelings of vigour and lessen emotional reactivity to environmental triggers. Future longitudinal research should be designed to capture SWB's dynamic nature and identify the roles personality and PWB play in determining SWB reactivity.

\section{Acknowledgements}

The authors thank the participants, Mr. Ross Bool and the Technical Services staff at the University of Southern Queensland's Department of Psychology.

\section{References}

Abbott, R. A., Croudace, T. J., Ploubidis, G. B., Kuh, D., Richards, M. \& Huppert, F. A (2008). The relationship between early personality and midlife psychological well-being: Evidence from a UK birth cohort study. Social Psychiatry and Psychiatric Epidemiology, Epub. 2008 April 28. doi:10.1007/s00127-008-0355-8. Abbott, R. A., Ploubidis, G. B., Huppert, F., Kuh, D., Wadsworth, M. E. J., \& Croudace, T J. (2006). Psychometric evaluation and predictive validity of Ryff's psychologica well-being items in a UK birth cohort sample of women. Health and Quality of Life Outcomes, 4, 76.

Burns, R. B. (1979). The self-concept theory in measurement, development and behavior. London: Longman.

Burns, R. A., \& Machin, M. A. (2009). Investigating the structural validity of Ryff's psychological well-being scales across two samples. Social Indicators Research, 93(2), 359-375. doi:10.1007/s11205-008-9329-1.

Byrne, B. M. (2001). Structural equation modeling with AMOS: Basic concepts, applications and programming. New Jersey: Lawrence Erlbaum Associates.
Clarke, P. J., Marshall, V. W., Ryff, C. D., \& Wheaton, B. (2001). Measuring psychological well-being in the Canadian Study of Health and Aging. International Psychogeriatrics, 13(Suppl. 1), 79-90.

Costa, P., \& McCrae, R. R. (1980). Influence of extraversion and neuroticism on subjective well-being: Happy and unhappy people. Journal of Personality and Social Psychology, 38, 668-678.

DeNeve, K. M., \& Cooper, H. (1998). The happy personality: A meta-analysis of 137 personality traits and subjective well-being. Psychological Bulletin, 124, 197-229.

Diener, E., \& Lucas, R. E. (1999). Personality and subjective well-being. In D. Kahneman, E. Diener, \& N. Schwarz (Eds.), Well-being: The foundations of hedonic psychology (pp. 213-229). New York: Russell Sage Foundation.

Fredrickson, B. L. (2003). The value of positive emotions. American Scientist, 91, 330-335.

Grucza, R. A., \& Goldberg, L. R. (2007). The comparative validity of 11 modern personality inventories: Predictions of behavioral acts, informant reports, and clinical indicators. Journal of Personality Assessment, 89, 167-187.

Headey, B. (2008). The set-point theory of well-being: Negative results and consequent revisions. Social Indicators Research, 85, 389-403.

Headey, B. W., \& Wearing, A. J. (1989). Personality, life events and subjective wellbeing: Toward a dynamic equilibrium model. Journal of Personality and Social Psychology, 57, 731-739.

Huppert, F. (2008). Psychological Wellbeing: Evidence regarding its causes and consequences - State-of-Science Review: SR-X2, Government Office for Science Foresight Project, Mental Capital and Wellbeing: Making the most of ourselves in the 21st Century, London.

Huppert, F. (2005). Positive mental health in individuals and populations. In F. Huppert, N. Baylis, \& B. Keverne (Eds.), The science of well-being (pp. 307-340). Oxford: Oxford University Press.

Judge, T. A., Erez, A., Bono, J. E., \& Thoresen, C. J. (2003). The core self-evaluations scale: Development of a measure. Personnel Psychology, 56, 303-331.

Kahneman, D. (1999). Objective happiness. In D. Kahneman, E. Diener, \& N. Schwarz (Eds.), Well-Being: The foundations of hedonic psychology (pp. 3-25). New York: Russell Sage.

Kling, K. C., Ryff, C. D., Love, G., \& Essex, M. (2003). Exploring the influence of personality on depressive symptoms and self-esteem across a significant life transition. Journal of Personality and Social Psychology, 85(5), 922-932.

Lykken, D. T., \& Tellegen, A. (1996). Happiness is a stochastic phenomenon. Psychological Science, 7, 186-189.

Lyubomirsky, S., \& Ross, L. (1999). Changes in attractiveness of elected, rejected, and precluded alternatives: A comparison of happy and unhappy individuals. Journal of Personality and Social Psychology, 76, 988-1007.

Ryan, R. M., \& Deci, E. L. (2001). On happiness and human potentials: A review of research on hedonic and eudaimonic well-being. Annual Review of Psychology, $52,141-166$.

Ryff, C. D. (1989). Beyond Ponce de Leon and life satisfaction: New directions in quest of successful aging. International Journal of Behavioral Development, 12, 35-55.

Ryff, C. D., \& Singer, B. (1998). The contours of positive human health. Psychological Inquiry, 9, 1-28.

Schmutte, P. S., \& Ryff, C. D. (1997). Personality and well-being: Reexamining methods and meanings. Journal of Personality and Social Psychology, 73, 549-559.

Seligman, M. E. P. (2003). Positive psychology: Fundamental assumptions. The Psychologist, 126, 127.

Springer, K. W., \& Hauser, R. M. (2006). An assessment of the construct validity of Ryff's scales of psychological well-being: Method, mode and measurement effects. Social Science Research, 35(4), 1079-1110.

Vittersø, J. (2001). Personality traits and subjective well-being: Emotional stability, not extraversion is probably the important predictor. Personality and Individual Differences, 31, 903-914.

Watson, D., Clark, L. A., \& Tellegen, A. (1988). Development and validation of brief measures of positive and negative affect: The PANAS scales. Journal of Personality and Social Psychology, 54, 1063-1070. 